\title{
Constrained-volume assembly of organometal confined in polymer to fabricate multi-heteroatom doped carbon for oxygen reduction reaction
}

\author{
Congling $\mathrm{Li}^{1}$, Jing Zhao ${ }^{1}$, Rodney D. Priestley ${ }^{2}$ and Rui Liu ${ }^{1 *}$
}

\begin{abstract}
The design and preparation of non-precious metal and carbon-based nanocomposites are critical to the development of efficient catalysts for technologies ranging from water splitting to fuel cell. Here, we present a constrained-volume self-assembly process for the one-step continuous precipitation-induced formation of soft colloidal particles, in which hydrophobic organoferrous compound, $\left(\mathrm{Ph}_{3} \mathrm{P}\right)_{2} \mathrm{Fe}(\mathrm{CO})_{3}$, is encapsulated within poly(styrene-co-acrylonitrile) nanoparticles (NPs). The protective and confining polymer matrix ensures uniform carbonization and dispersion of $\left(\mathrm{Ph}_{3} \mathrm{P}\right)_{2} \mathrm{Fe}(\mathrm{CO})_{3}$ within a carbon matrix after a pyrolysis process. The obtained carbon NPs are successfully co-doped with $\mathrm{Fe}, \mathrm{P}$ and $\mathrm{N}$ with a relatively high surface area of $\sim 380 \mathrm{~m}^{2} \mathrm{~g}^{-1}$. The Fe-P-N-doped carbon catalyst exhibits high catalytic performance and stability toward oxygen reduction reaction in both alkaline and acidic electrolytes via a favorable four-electron pathway. Meanwhile, the catalytic capability of Fe-P-N-doped carbon can be tailored by the tunable nanostructures.
\end{abstract}

Keywords: heteroatom doping, carbon, constrained-volume, self-assembly, electrocatalyst

\section{INTRODUCTION}

Owing to the high power density and energy-conversion efficiency, fuel cells have been regarded as one of the most promising and available energy conversion technologies with nearly no environmental contamination $[1,2]$. Currently, Pt based nanomaterials are considered to be the most efficient electrocatalyst for cathodic oxygen reduction reaction (ORR) in proton exchange membrane fuel cells (PEMFCs) $[3,4]$. Nevertheless, high cost, limited supply, and low stability of Pt catalyst still greatly hamper their commercialization. Alternatively, a great number of efforts have been made to the design and synthesis of heteroatom doped carbon as an efficient catalyst [5-11]. For example, $\mathrm{N}$-doped carbon materials exhibit good performance towards ORR as $\mathrm{O}_{2}$ species are easily reduced on the positively charged $\mathrm{C}$ neighboring $\mathrm{N}$ atoms [12-14]. Moreover, more active sites with varied charge density were introduced when a small amount of transition metal (e.g., $\mathrm{Fe}, \mathrm{Ni}$, or $\mathrm{Co}$ ) and $\mathrm{N}$ were co-doped in carbon matrix. Therefore, co-doping of metal and nonmetal elements would be beneficial to various electrochemical processes [15-18].

Polyacrylonitrile (PAN) is a widely used polymer precursor for carbon with inherent $\mathrm{N}$ dopant [19]. However, strong dipole-dipole interaction between the highly polar nitrile groups endows PAN low solubility and limits most of PAN structures to a fibrous morphology [20]. One strategy to improve the solubility and the ability in microphase-separated nanostructures is to incorporate soft polymer block into PAN backbone. A series of PANbased copolymers, such as poly(acrylonitrile- $b$-butyl acrylate), were prepared and expanded the possibility of copolymer self-assembly. At the same time, the derived carbon materials present varied morphologies and structures [21-23]. On the other hand, the general preparation of PAN-derived carbon/metal nanocomposites involves multiple steps: i) PAN carbonization into carbon nanofiber (CNF); ii) functionalization of CNF; iii) subsequent dispersion of metal nanoparticles (NPs) [24]. An in-situ encapsulation method would avoid the tedious steps of post-modification as well as facilitate the uniform

\footnotetext{
${ }^{1}$ Ministry of Education Key Laboratory of Advanced Civil Engineering Materials, School of Materials Science and Engineering and Institute for Advanced Study, Tongji University, Shanghai 201804, China

${ }^{2}$ Department of Chemical and Biological Engineering, and Princeton Institute for the Science and Technology of Materials, Princeton University, Princeton, NJ 08544, USA

* Corresponding author (email: ruiliu@tongji.edu.cn)
} 
dispersion of metallic NPs within the framework of CNFs. For example, Huang and coworkers [25] have directly electrospun a mixture of PAN and $\mathrm{Pd}(\text { acetate })_{2}$, followed by carbonization. The obtained Pd/CNF composites exhibited good performance towards the reduction of $\mathrm{H}_{2} \mathrm{O}_{2}$ and the oxidation of nicotinamide adenine dinucleotide (NADH).

The rational design and processing of multi-doped carbon derived from PAN-based polymers and metal precursors remains a challenge in the production of efficient nanocomposites for catalytic ORR. Here, we report a novel polymer processing technique, constrain-volume self-assembly, for co-precipitation of poly(styrene-co-acrylonitrile) (PS-c-PAN) (see Fig. S1a in Supplementary information) with a hydrophobic organoferrous compound, $\left(\mathrm{Ph}_{3} \mathrm{P}\right)_{2} \mathrm{Fe}(\mathrm{CO})_{3}$ (Fig. S1b). By confining a rapid self-assembly to small volume, we are able to overcome the different speeded phase-separation and produce hydrophobic organometallic species confined within a polymer assembly with a high efficiency. Pyrolysis of the PS-c-PAN NPs entrapped $\left(\mathrm{Ph}_{3} \mathrm{P}\right)_{2} \mathrm{Fe}(\mathrm{CO})_{3}$ results in carbon nanomaterials with co-doping of $\mathrm{Fe}, \mathrm{P}$ and $\mathrm{N}$ with a relatively high surface area. We demonstrate that the obtained Fe-P-N-doped carbon catalysts show an enhanced electrocatalytic activity and durability for ORR with tailoring capability.

\section{EXPERIMENTAL SECTION}

\section{Materials synthesis}

All the reagents were analytical grade. $\left(\mathrm{Ph}_{3} \mathrm{P}\right)_{2} \mathrm{Fe}(\mathrm{CO})_{3}$ was prepared according to the previously reported method [26]. $\left(\mathrm{Ph}_{3} \mathrm{P}\right)_{2} \mathrm{Fe}(\mathrm{CO})_{3} @ \mathrm{PS}-\mathrm{c}-\mathrm{PAN}$ NPs were prepared via flash nanoprecipitation (FNP) using an impinging jet mixer. In detail, Stream 1 contained $3 \mathrm{mg}$ PSc-PAN and $5 \mathrm{mg}\left(\mathrm{Ph}_{3} \mathrm{P}\right)_{2} \mathrm{Fe}(\mathrm{CO})_{3}$ dissolved in $2 \mathrm{~mL}$ of THF, while Stream 2 contained $2 \mathrm{~mL}$ of water. The two input streams were expelled from both syringes with the same rate $\left(\sim 37 \mathrm{~mL} \mathrm{~s}^{-1}\right)$, causing two streams to merge and drop into a beaker filled with $20 \mathrm{~mL} \mathrm{H}_{2} \mathrm{O} .\left(\mathrm{Ph}_{3} \mathrm{P}\right)_{2} \mathrm{Fe}$ $(\mathrm{CO})_{3} @ P S-c-P A N$ NPs were collected by centrifugation and then dried at $60^{\circ} \mathrm{C}$. Then the dried NPs were placed in a tube furnace and stabilized at $280^{\circ} \mathrm{C}$ for $1 \mathrm{~h}$ in air with heating rate of $5^{\circ} \mathrm{C} \mathrm{min}{ }^{-1}$ and carbonized at $800^{\circ} \mathrm{C}$ for $2 \mathrm{~h}$ under $\mathrm{N}_{2}$ flow with a heating rate of $5^{\circ} \mathrm{C} \mathrm{min}^{-1}$. This as-prepared Fe-P-N-doped carbon was designated as FNP-5. FNP-3 and FNP-1 were prepared using the same procedure except varying the amount of 3 or $1 \mathrm{mg}$ $\left(\mathrm{Ph}_{3} \mathrm{P}\right)_{2} \mathrm{Fe}(\mathrm{CO})_{3}$ dissolved in $2 \mathrm{~mL}$ of THF for Stream 1, respectively. Pure PS-c-PAN NPs were prepared using the same FNP procedure except that only PS-c-PAN polymer in Stream 1. A control experiment was carried out by slow addition of $\mathrm{H}_{2} \mathrm{O}(2 \mathrm{~mL})$ into THF $(2 \mathrm{~mL})$ mixture of $3 \mathrm{mg}$ PS-c-PAN and $5 \mathrm{mg}\left(\mathrm{Ph}_{3} \mathrm{P}\right)_{2} \mathrm{Fe}(\mathrm{CO})_{3}$.

\section{Characterization}

$\mathrm{X}$-ray diffraction (XRD) patterns were recorded on a $\mathrm{D} /$ MAX 2550 powder diffractometer (D/max $2550 \mathrm{~V}$, Rigaku, Tokyo, Japan), using $\mathrm{Cu}$ Ka radiation. Transmission electron microscopy (TEM) images and high-resolution TEM (HRTEM) images were conducted on a JEM-2100 F electron microscope (JEOL, Japan) at an acceleration voltage of $200 \mathrm{kV}$. Nitrogen adsorption-desorption isotherms were performed with a Quadrachrome adsorption instrument (Autosorb-iQ3; Quantachrome, America) at $77 \mathrm{~K}$. The specific surface area was calculated by using the adsorption data via the Brunauer-Emmett-Teller (BET) method. The pore size distribution and the total pore volume were derived from the related adsorption branch by using the Barrett-Joyner-Halenda (BJH) model. X-ray photoelectron spectroscopic (XPS) analysis was performed on a ESCALAB 250Xi operated at $120 \mathrm{~W}$.

\section{Electrochemical characterization}

The electrochemical activities of Fe-P-N-doped carbon for ORR were measured at room temperature by using a CHI-760E electrochemical analyzer with a three-electrode cell system. A glassy carbon disk electrode $(5 \mathrm{~mm}$ in diameter, Pine Instrument Co., USA) coated with Fe-P$\mathrm{N}$-doped carbon was employed as working electrode, while a $\mathrm{Ag} / \mathrm{AgCl}$ (saturated $\mathrm{KCl}$ ) and Pt electrode were used as reference and counter electrode in the measurement, respectively. For preparation of the working electrode, the catalyst inks were prepared by dispersing $10 \mathrm{mg}$ Fe-P-N-doped carbon or commercial Pt/C-JM catalyst (Johnson Matthey, $20 \mathrm{wt} \% \mathrm{Pt}$ ) in a mixture of $1.25 \mathrm{~mL}$ ethanol and $0.03 \mathrm{~mL}$ Nafion (5\%), and the desired amount of such catalyst inks as deposited onto the polished glassy carbon electrode and dried at room temperature before measurement.

Cyclic voltammetry (CV) and rotating ring disk electrode (RRDE) techniques for ORR were carried out in $\mathrm{O}_{2}$ saturated $0.1 \mathrm{~mol} \mathrm{~L}^{-1} \mathrm{KOH}$ solution or $0.1 \mathrm{~mol} \mathrm{~L}^{-1} \mathrm{HClO}_{4}$ solution. The loadings of Fe-P-N-doped carbon on the working electrode were 0.36 and $0.60 \mathrm{mg} \mathrm{cm}^{-2}$ in $\mathrm{O}_{2}$-saturated $0.1 \mathrm{~mol} \mathrm{~L}^{-1} \mathrm{KOH}$ and $0.1 \mathrm{~mol} \mathrm{~L}^{-1} \mathrm{HClO}_{4}$, respectively. The loadings of $\mathrm{Pt} / \mathrm{C}(20 \mathrm{wt} . \%)$ catalysts on the working electrode were $0.10 \mathrm{mg} \mathrm{cm}^{-2}$ in both electrolytes. For all the CVs, linear sweep voltammetry (LSV), and chronoamperometric measurements, the scan rate was 
$10 \mathrm{mV} \mathrm{s}^{-1}$. All potentials in this study were reported with respect to the reversible hydrogen electrode (RHE).

Hydrogen peroxide yields and the electron transfer number $(n)$ were calculated using the equations below:

$$
\begin{gathered}
n=\frac{4 I_{\mathrm{D}}}{I_{\mathrm{D}}+I_{\mathrm{R}} / N}, \\
\% \mathrm{HO}_{2}{ }^{-}=200 \times \frac{I_{\mathrm{R}} / N}{I_{\mathrm{D}}+I_{\mathrm{R}} / N},
\end{gathered}
$$

where $I_{\mathrm{D}}, I_{\mathrm{R}}$ and $N$ are the disk current, ring current and the ring collection efficiency, respectively. In this measurement, $N=0.37$.

\section{RESULTS AND DISCUSSION}

\section{Synthesis, structure, and composition of materials}

Constrained-volume self-assembly is a continuous process exploiting an impinging jet mixer to bring about the precipitation of polymers under turbulent conditions [27-29]. The process is different from the slow time scale of solvent exchange and thermodynamic equilibrium of polymer assembly in conventional solution self-assembly. The polymer solution confined within a small volume would rapidly mix with the non-solvent in millisecond time-scale to induce self-assembly of polymers into kinetically frozen NPs [30,31]. As a result, the rapid mixing of polymers with active ingredients would avoid the diffusion-limited formation of polymer micelles and precipitates of ingredients. Thus, instead of individually separated ensembles, a composite structure is co-assembled in which small aggregate of active ingredients are entrapped within a polymer shell [32]. Using this technique, also termed FNP, Prud'homme and coworkers [33-36] have successfully incorporated hydrophobic drugs, fluorophores and inorganic NPs within block copolymer ensembles. In addition, Priestley and coworkers [37-39] have exploited FNP to process a series of polymer NPs ranging from homogeneous latex to patchy colloids.

Fig. 1 illustrated the schematic process of one-step constrained-volume self-assembly, in which polymer and metal precursors assembled into organometal@polymer colloids in a controllable manner by confining the volume and time scale of mixing. In detail, a confined impinging jet (CIJ) mixer was used to achieve a rapid mixing within a confined space. The interior structure of $\mathrm{CIJ}$ mixer is Tshape mixer (Fig. S2), where syringe pumps are employed to drive two opposing liquid streams at high velocity and collide in the mixing chamber $[40,41]$. A syringe containing PS-c-PAN and $\left(\mathrm{Ph}_{3} \mathrm{P}\right)_{2} \mathrm{Fe}(\mathrm{CO})_{3}$ dissolved in THF was placed at the inlet of stream 1 , and a syringe con-

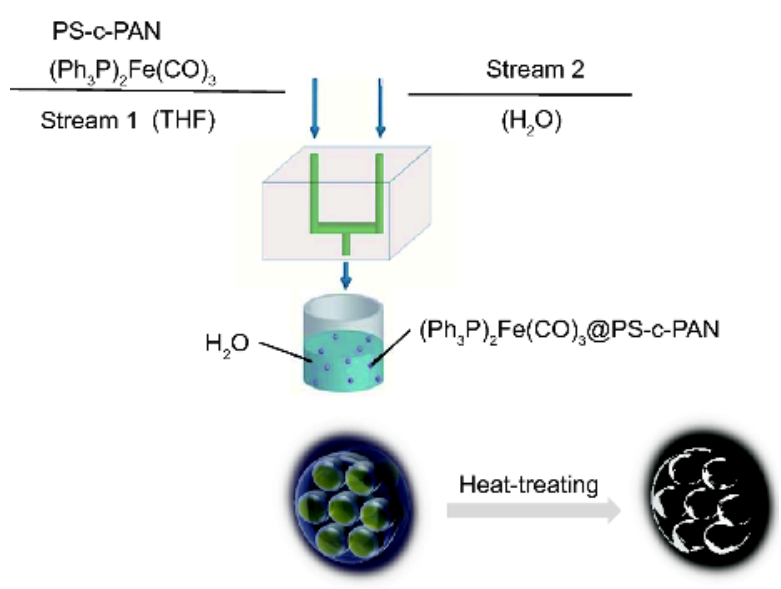

Figure 1 Schematic illustration of constrained-volume self-assembled $\left(\mathrm{Ph}_{3} \mathrm{P}\right)_{2} \mathrm{Fe}(\mathrm{CO})_{3} @ P S-c-P A N$ NPs and conversion into Fe-P-N-doped carbon materials.

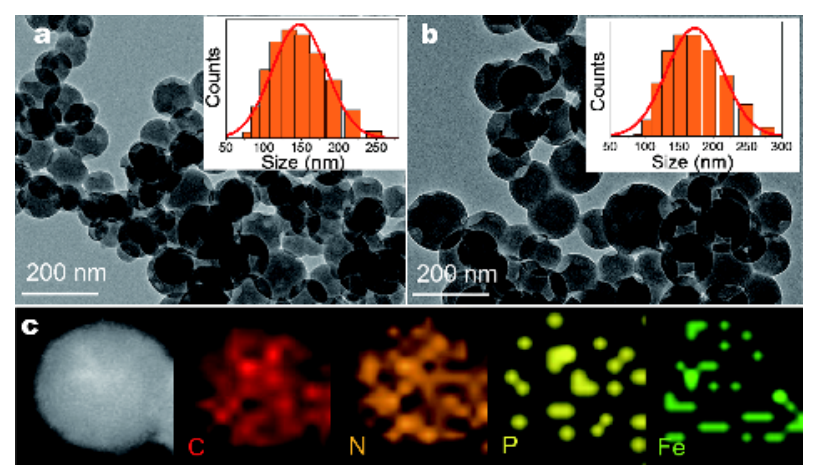

Figure 2 TEM images of (a) pure PS-c-PAN NPs; (b) $\left(\mathrm{Ph}_{3} \mathrm{P}\right)_{2} \mathrm{Fe}$ $(\mathrm{CO})_{3} @ P S-c-P A N$ NPs. (c) STEM and elemental mapping of $\left(\mathrm{Ph}_{3} \mathrm{P}\right)_{2} \mathrm{Fe}$ $(\mathrm{CO})_{3} @ P S-c-P A N$ NPs.

taining $\mathrm{H}_{2} \mathrm{O}$ was placed at the inlet of stream 2. Subsequently, fluid was expelled manually from both syringes at the same rate $\left(\sim 1 \mathrm{~mL} \mathrm{~s}^{-1}\right)$, causing the two streams to merge and then be diluted into a water reservoir. The water reservoir quenched the precipitated NPs and a stable colloid solution was formed. After steps of purification, stabilization and further carbonization, Fe-P-Ndoped carbon composites were obtained.

The TEM image in Fig. 2a shows that the pure PS-cPAN NPs through FNP are spherical in shape with the average diameter of $\sim 140 \mathrm{~nm}$. Simultaneous feeding of both PS-c-PAN and $\left(\mathrm{Ph}_{3} \mathrm{P}\right)_{2} \mathrm{Fe}(\mathrm{CO})_{3}$ leads to an increase of NP size to $\sim 175 \mathrm{~nm}$ (Fig. 2b), which comes from the expanded volume after $\left(\mathrm{Ph}_{3} \mathrm{P}\right)_{2} \mathrm{Fe}(\mathrm{CO})_{3}$ encapsulation. No other precipitates or side-products are observed, indicating high encapsulation efficiency. Scanning transmission electron microscopy (STEM) with elemental 


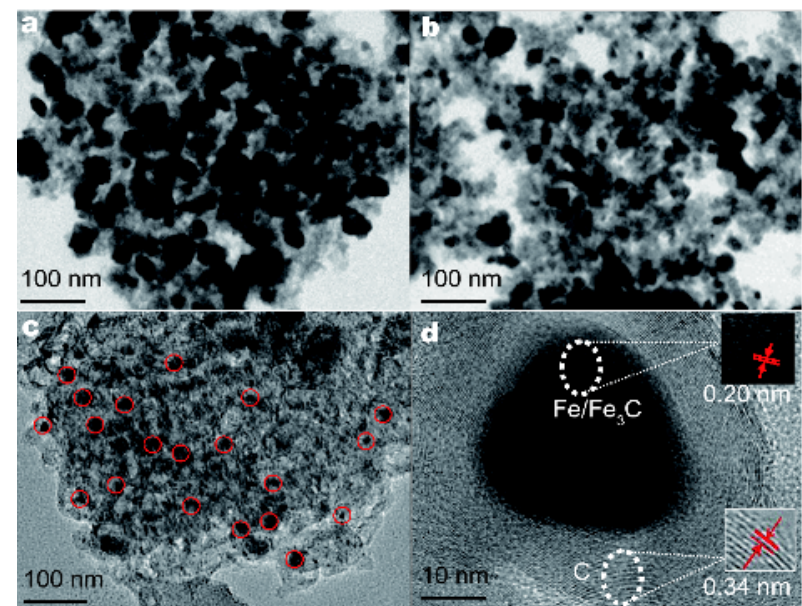

Figure 3 TEM images of (a) FNP-5, (b) FNP-3 and (c) FNP-1; (d) corresponding HRTEM images of FNP-5.

mapping results revealed a homogeneous distribution of $\mathrm{P}$ and Fe elements within a PS-c-PAN NP (Fig. 2c).

A control experiment was carried out by slow addition of $\mathrm{H}_{2} \mathrm{O}$ into a THF mixture of $\left(\mathrm{Ph}_{3} \mathrm{P}\right)_{2} \mathrm{Fe}(\mathrm{CO})_{3}$ and PS-cPAN. The obtained NPs (Fig. S3a) possess irregular morphologies while clusters of $\left(\mathrm{Ph}_{3} \mathrm{P}\right)_{2} \mathrm{Fe}(\mathrm{CO})_{3}$ are visible and dispersed on the surface of polymer, which results from the different precipitation kinetics of the two compounds during a slow self-assembly process. Hence, the formation of $\left(\mathrm{Ph}_{3} \mathrm{P}\right)_{2} \mathrm{Fe}(\mathrm{CO})_{3} @ P S-c-P A N \quad N P s$ through FNP can be envisioned as follows: solvent exchange in confined-volume is faster than the aggregation process of $\left(\mathrm{Ph}_{3} \mathrm{P}\right)_{2} \mathrm{Fe}(\mathrm{CO})_{3}$ while at the same time, rapid mixing balances the timescale of $\left(\mathrm{Ph}_{3} \mathrm{P}\right)_{2} \mathrm{Fe}(\mathrm{CO})_{3}$ nucleation and growth with the timescale of polymer self-assembly, ensuring the formation of $\left(\mathrm{Ph}_{3} \mathrm{P}\right)_{2} \mathrm{Fe}(\mathrm{CO})_{3} @ \mathrm{PS}-\mathrm{c}-$ PAN NPs.

Carbonization at high temperature leads to the con- version of PS-c-PAN encapsulated $\left(\mathrm{Ph}_{3} \mathrm{P}\right)_{2} \mathrm{Fe}(\mathrm{CO})_{3} \mathrm{NPs}$ into Fe-P-N-doped carbon. FNP-5, FNP-3 and FNP-1 are denoted as a series of Fe-P-N-doped carbon obtained from different organoferrous feed amounts of 5, 3 and $1 \mathrm{mg}$ in stream 1, respectively, while pure carbon NPs (denoted as FNP-0, TEM image shown in Fig. S3b) were also prepared by pyrolyzing pure PS-c-PAN NPs through FNP (see experimental details in SI). TEM image of FNP5 in Fig. 3 a shows that Fe-based NPs with average size of $\sim 40 \mathrm{~nm}$ were uniformly dispersed inside a carbon matrix. Element mapping in Fig. S4 indicates that Fe, $\mathrm{N}$ and $\mathrm{P}$ elements were uniformly distributed within carbon matrix. An HRTEM image (Fig. 3d) displays clear lattice fringes with interplanar spacing of 0.20 and $0.34 \mathrm{~nm}$, consistent with the (031) basal planes of crystalline $\mathrm{Fe}_{3} \mathrm{C}$ or (110) planes of cubic $\mathrm{Fe}$ and the (002) plane of graphitic C, respectively [42]. The XRD results confirm the existence of $\mathrm{Fe}_{3} \mathrm{C}$ (JCPDS No. 85-1317) and graphitized carbon, as shown in Fig. S5a.

The confinement effect of PS-c-PAN shell makes the $\left(\mathrm{Ph}_{3} \mathrm{P}\right)_{2} \mathrm{Fe}(\mathrm{CO})_{3}$ well protected during carbonization and results in a uniform distribution of carbonized products among the carbon matrix. The results demonstrate the successful encapsulation of $\left(\mathrm{Ph}_{3} \mathrm{P}\right)_{2} \mathrm{Fe}(\mathrm{CO})_{3}$ inside PS-cPAN NPs during FNP. The effect of processing parameters on the preparation was studied by decreasing the feeding amount of $\left(\mathrm{Ph}_{3} \mathrm{P}\right)_{2} \mathrm{Fe}(\mathrm{CO})_{3}$ in stream 1. As shown in Fig. 3b, c, FNP-3 and FNP-1 from lower $\left(\mathrm{Ph}_{3} \mathrm{P}\right)_{2} \mathrm{Fe}-$ $(\mathrm{CO})_{3}$ feed concentrations retain a good dispersion of $\mathrm{Fe}$ based NPs while the size decreases to 15 and $5 \mathrm{~nm}$, respectively. Meanwhile, a sparser distribution of $\mathrm{Fe}_{3} \mathrm{C} \mathrm{NPs}$ within the carbon support is observed when lowering the $\left(\mathrm{Ph}_{3} \mathrm{P}\right)_{2} \mathrm{Fe}(\mathrm{CO})_{3}$ feed concentration in stream 1, indicating the ability to tune the metal NPs arrangement by changing process conditions.

Raman spectra in Fig. 4a exhibit two obvious peaks
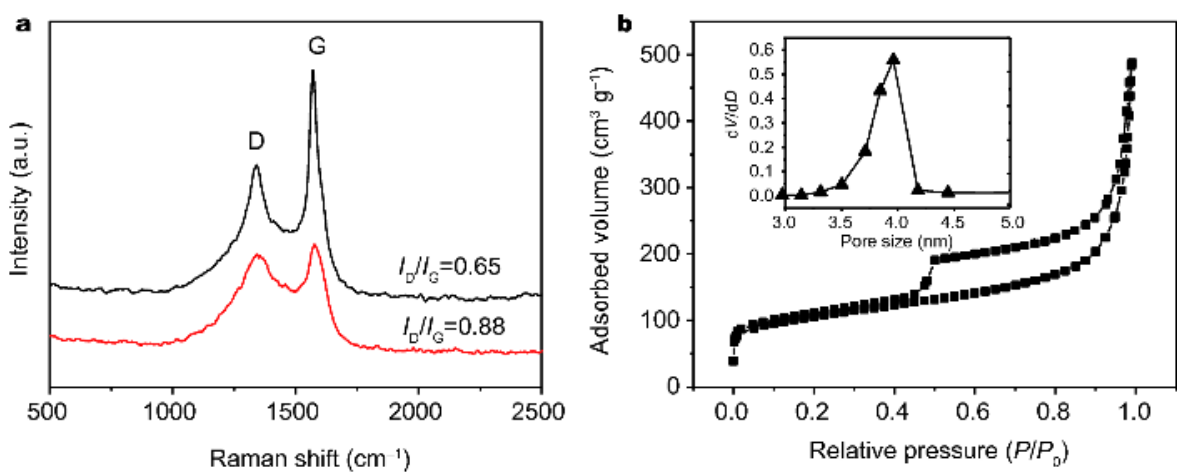

Figure 4 (a) Raman spectra of FNP-5 (lack line) and FNP-0 (red line); (b) $\mathrm{N}_{2}$ sorption isotherm and pore size distribution (inset) of FNP-5. 

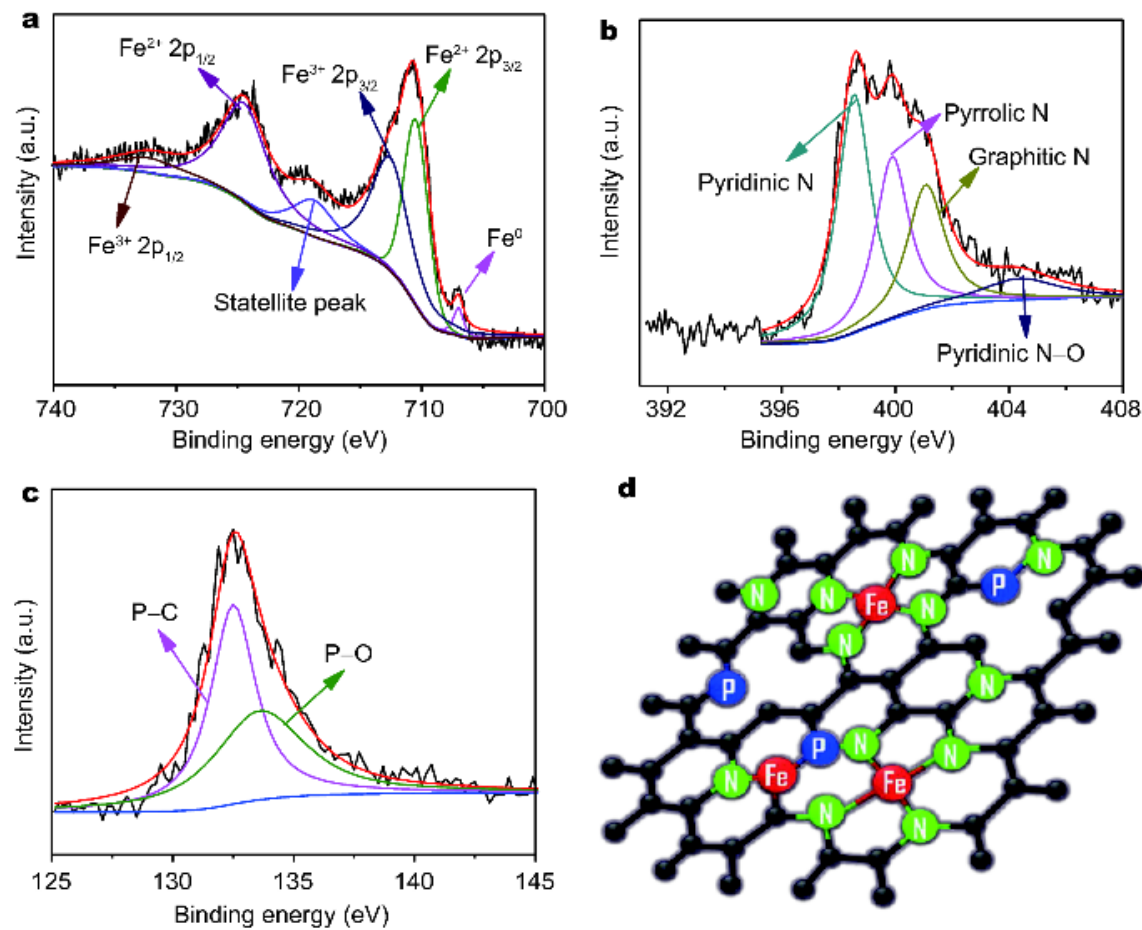

Figure 5 Deconvoluted high resolution XPS of FNP-5: (a) Fe 2p, (b) N 1s and (c) P 2p; (d) a simplified model of Fe-P-N doped carbon (green ball: N; blue ball: P; red ball: Fe; black ball: C).

around 1,330 and $1,580 \mathrm{~cm}^{-1}$, corresponding to $\mathrm{D}$ and $\mathrm{G}$ band for carbon [43]. Fe and $\mathrm{P}$ doping lead to a smaller $I_{\mathrm{D}} / I_{\mathrm{G}}$ value of FNP-5 compared with that of FNP-0, suggesting a higher graphitization degree after co-doping [44]. $\mathrm{N}_{2}$ sorption isotherms of FNP-5 in Fig. $4 \mathrm{~b}$ show a type IV isotherm and a $\mathrm{H}_{4}$-type hysteresis loop with a relatively high surface area of $\sim 380 \mathrm{~m}^{2} \mathrm{~g}^{-1}$ and a pore size of $\sim 4 \mathrm{~nm}$, revealing the mesoporous structure derived from the degradation of PS during carbonization. XPS spectra of FNP-5 in Fig. S5b confirm the co-existence of Fe (1.3 at\%), P (3.9 at\%) and $\mathrm{N}$ (6.1 at\%) in the carbon matrix. The peaks of Fe 2 p spectrum (Fig. 5b) at 706.9, $710.4,712.7,724.6$ and $729.9 \mathrm{eV}$ are corresponding to metallic $\mathrm{Fe}, \mathrm{Fe}^{2+} 2 \mathrm{p}_{3 / 2}, \mathrm{Fe}^{3+} 2 \mathrm{p}_{3 / 2}, \mathrm{Fe}^{2+} 2 \mathrm{p}_{1 / 2}$ and $\mathrm{Fe}^{3+} 2 \mathrm{p}_{1 / 2}$, indicating the binding state between iron and nitrogen, phosphorus or carbon $[45,46]$. In addition, the existence of metallic Fe can boost the activity of $\mathrm{Fe}-\mathrm{N}_{x}$ and plays an important role in enhancing the ORR activity of the catalysts [47]. In the high-resolution N 1s spectrum (Fig. $5 b)$, the four deconvoluted peaks near 398.4, 399.9, 401.1 and $404.3 \mathrm{eV}$ are attributed to pyridinic-, pyrrolic-, graphitic- $\mathrm{N}$, and pyridine $\mathrm{N}-\mathrm{O}$, respectively $[48,49]$. The deconvoluted P 2p spectrum (Fig. 5c) reveals two peaks at 133.1 and $134.1 \mathrm{eV}$, assigned to isolated $\mathrm{P}-\mathrm{C}$ and surface
$\mathrm{P}-\mathrm{O}$ species, respectively. The successful doping of $\mathrm{P}$ and Fe is believed to arise from $\left(\mathrm{Ph}_{3} \mathrm{P}\right)_{2} \mathrm{Fe}(\mathrm{CO})_{3}$ while $\mathrm{N}$ from PS-c-PAN. Moreover, the entrapment of $\left(\mathrm{Ph}_{3} \mathrm{P}\right)_{2} \mathrm{Fe}(\mathrm{CO})_{3}$ in PS-c-PAN guarantees a synergetic effect for carbonization into Fe-N-P-doped carbon: i) uniformly encapsulation of organometallic precursor in PS-c-PAN results in the well-dispersed dopants (e.g., Fe, N, P) within carbon matrix; ii) pyrolyzing active ingredients within a confined space bestows a high doping efficiency; iii) sufficient reaction between each element occurring in a nano-confinement leads to the formation of active metal $\mathrm{Fe}$ NPs, $\mathrm{Fe}_{3} \mathrm{C}, \mathrm{Fe}-\mathrm{P}, \mathrm{Fe}-\mathrm{N}$, and $\mathrm{N}-\mathrm{P}$ in the doped carbon materials (as shown in a molecular model of Fig. 5d) for electrochemical applications.

\section{Electrocatalytic performance of catalysts}

Electrocatalytic performances of FNP-5, FNP-3, FNP-1 and commercial $\mathrm{Pt} / \mathrm{C}$ for $\mathrm{ORR}$ were investigated and compared in both $\mathrm{O}_{2}$-saturated $0.1 \mathrm{~mol} \mathrm{~L}^{-1} \mathrm{KOH}$ and $0.1 \mathrm{~mol} \mathrm{~L}^{-1} \mathrm{HClO}_{4}$ electrolyte solution. ORR peak $E_{\mathrm{p}}$ (Fig. $6 \mathrm{a})$ and half-wave potential $E_{1 / 2}$ (Fig. 6b) are observed for FNP-1 $\quad\left(E_{\mathrm{p}}=0.80 \mathrm{~V} ; \quad E_{1 / 2}=0.78 \mathrm{~V}\right), \quad$ FNP-3 $\quad\left(E_{\mathrm{p}}=0.83 \mathrm{~V}\right.$; $\left.E_{1 / 2}=0.81 \mathrm{~V}\right)$ and FNP-5 $\left(E_{\mathrm{p}}=0.85 \mathrm{~V} ; E_{1 / 2}=0.83 \mathrm{~V}\right)$ in $0.1 \mathrm{~mol} \mathrm{~L}^{-1} \mathrm{KOH}$. It is noted that the half-wave potential 

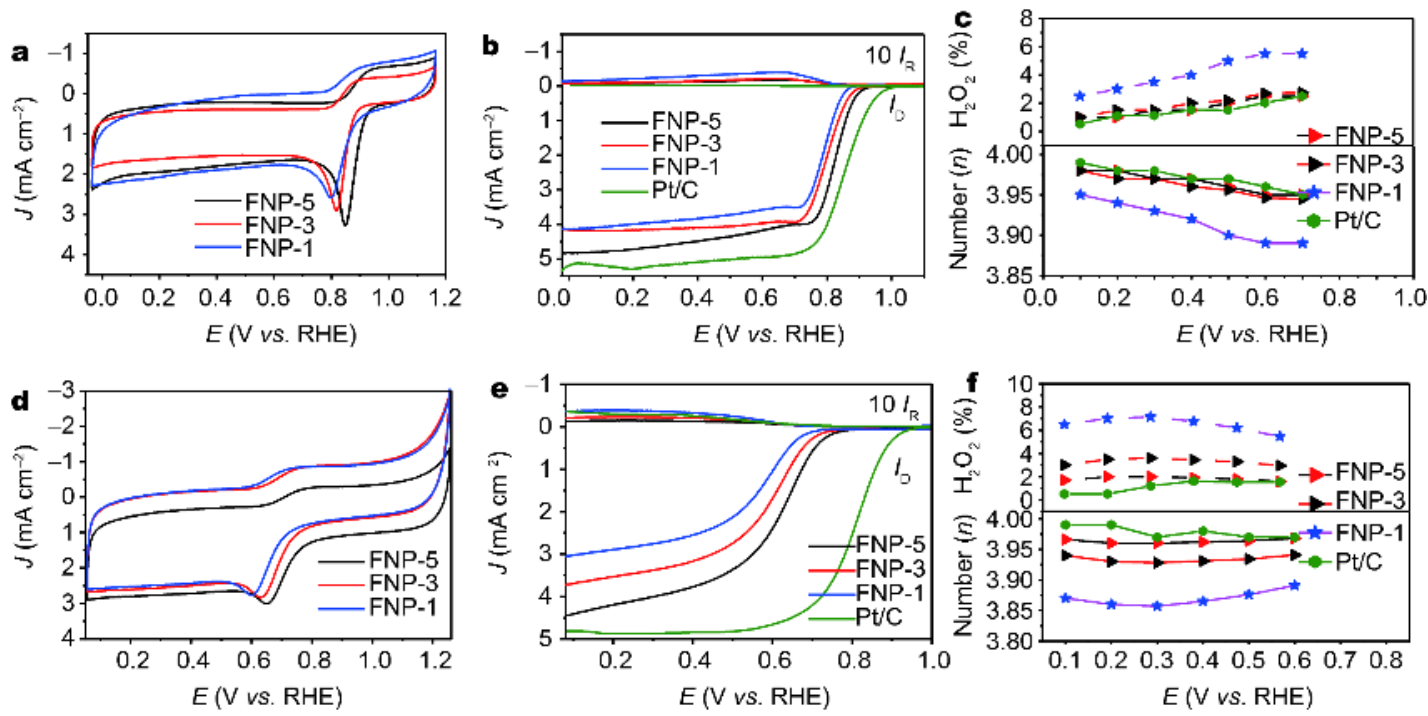

Figure $6 \mathrm{CV}$ curves of the prepared Fe-P-N-doped carbon in $\mathrm{O}_{2}$-saturated (a) $0.1 \mathrm{~mol} \mathrm{~L}^{-1} \mathrm{KOH}$ and (d) $0.1 \mathrm{~mol} \mathrm{~L}^{-1} \mathrm{HClO}_{4}$. $\mathrm{RRDE}$ polarization curves for Fe-P-N-doped carbon and commercial Pt/C at 1,600 rpm in $\mathrm{O}_{2}$-saturated (b) $0.1 \mathrm{~mol} \mathrm{~L}^{-1} \mathrm{KOH}$ and (e) $0.1 \mathrm{~mol} \mathrm{~L}^{-1} \mathrm{HClO}_{4}$. Calculated peroxide yields and theelectron transfer number based on the corresponding RRDE polarization curves in $\mathrm{O}_{2}$-saturated(c) $0.1 \mathrm{~mol} \mathrm{~L}^{-1} \mathrm{KOH}$ and (f) $0.1 \mathrm{~mol} \mathrm{~L} \mathrm{~L}^{-1}$ $\mathrm{HClO}_{4}$.

of FNP-5 is close to that of commercial $20 \mathrm{wt} \% \mathrm{Pt} / \mathrm{C}$ $\left(E_{1 / 2}=0.85 \mathrm{~V}\right)$. In Fig. $6 c, \mathrm{H}_{2} \mathrm{O}_{2}$ yields for FNP-1, FNP-3, FNP-5 and $\mathrm{Pt} / \mathrm{C}$ are $4 \%, 2 \%, 1.5 \%$ and $1.5 \%$, and the corresponding electron transfer number are 3.92, 3.96, 3.97 and 3.97, respectively. When tested in $0.1 \mathrm{~mol} \mathrm{~L}^{-1}$ $\mathrm{HClO}_{4}, \mathrm{FNP}-5, \mathrm{FNP}-3$ and FNP-1 show ORR peak at $0.65,0.63$ and $0.60 \mathrm{~V}$ (see Fig. $6 \mathrm{~d}$ ), and a half-wave potential at $0.63,0.61$, and $0.58 \mathrm{~V}$ (Fig. $6 \mathrm{e}$ ). $\mathrm{H}_{2} \mathrm{O}_{2}$ yields in $\mathrm{HClO}_{4}$ for FNP-1, FNP-3, FNP-5 and Pt/C are 6.7\%, $3.4 \%, 1.9 \%$ and $2.3 \%$, and the corresponding electron transfer numbers are 3.86, 3.93, 3.96 and 3.95, respectively (Fig. 6f). While further increasing the feeding amount of organoferrous to $7 \mathrm{mg}$, Fe-based NPs in FNP7 with average size of $\sim 100 \mathrm{~nm}$ dispersed inside a carbon matrix could be observed in Fig. S6a. FNP-7 shows comparable ORR activity to FNP-5 (Fig. S6b-d), indicating that the density of accessible active sites reached a maximum value in both FNP-5 and FNP-7.

It is worth noting that FNP-5 shows the lowest $\mathrm{H}_{2} \mathrm{O}_{2}$ yield and a nearly 4 electron process either in alkaline or acidic medium, indicating it possesses a similar ORR kinetics to commercial Pt/C. On the other hand, the series of FNP catalysts reported herein demonstrate excellent catalytic performance compared to the reported Fe-P-C, Fe-N-C and P-N-C catalysts [50-52]. The outstanding performance is mainly attributed to the unique composition and structure of the nanocomposites through constrained-volume self-assembly. Firstly, the organo- metal and polymer precursors contain a diversity of active elements, leading to a variety of energetic centers such as $\mathrm{Fe}-\mathrm{C}, \mathrm{Fe}-\mathrm{P}, \mathrm{Fe}-\mathrm{N}, \mathrm{N}-\mathrm{P}$ and $\mathrm{N}-\mathrm{C}$ for electrochemical process $[47,50,51]$. At the same time, the polymer coating leads to the uniform distribution of Fe-based NPs within the carbon matrix and a strong interaction between them. The voids due to the volatilization of PS blocks make the active sites more accessible. All these advantages make FNP-5 an efficient ORR catalyst that is comparable to the recently reported doped carbon catalysts $[43,48,53]$. Another unique feature of our materials is the catalytic tunability when co-feeding different concentrations of organometallic compound, resulting in the controllable amount of metal, size distribution and particle dispersion in doped-carbon catalysts.

Methanol crossover property and durability of FNP-5 were also investigated. No notable changes for the halfwave potential and current density were observed in the presence of $2 \mathrm{wt} \%$ methanol in both alkaline and acidic medium (Fig. S7a, d). By contrast, a significant half-wave potential decrease of the commercial $\mathrm{Pt} / \mathrm{C}$ was observed after the injection of methanol (Fig. S7b, e). The comparison clearly demonstrates a better tolerance to methanol crossover for FNP-5. The durability of the FNP-5 for ORR was also evaluated (Fig. S7c, f). The current density of FNP-5 shows a low decay (about $4 \%$ in $0.1 \mathrm{~mol} \mathrm{~L}^{-1} \mathrm{KOH}$ and $15 \%$ in $0.1 \mathrm{~mol} \mathrm{~L}^{-1} \mathrm{HClO}_{4}$ ) after running for $20,000 \mathrm{~s}$. In contrast, the current on $\mathrm{Pt} / \mathrm{C}$ 
suffered a $25 \%$ loss in $0.1 \mathrm{~mol} \mathrm{~L}^{-1} \mathrm{KOH}$ and $33 \%$ loss in $0.1 \mathrm{~mol} \mathrm{~L}^{-1} \mathrm{HClO}_{4}$ after running for $10,000 \mathrm{~s}$, respectively. It is apparent that FNP-5 exhibits an excellent stability compared to the commercial $\mathrm{Pt} / \mathrm{C}$. The better catalytic stability of FNP-5 is related to the lower $\mathrm{H}_{2} \mathrm{O}_{2}$ yields of ORR over FNP-5 (Fig. 6c, f). However, owing to the easypoisoning property of nanosized Pt metal and the exfoliation of Pt metal from carbon supports [54], the commercial $\mathrm{Pt} / \mathrm{C}$ catalyst suffers more loss of current density than FNP-5.

Another advantage of FNP is its characteristics of continuous-flow, making the whole process controllable and scalable. As shown in video S1, a CIJ mixer and a high-precision programmable syringe pump were used to scale up the synthesis process. Stream 1 containing THF solution of PS-c-PAN and $\left(\mathrm{Ph}_{3} \mathrm{P}\right)_{2} \mathrm{Fe}(\mathrm{CO})_{3}$ and stream 2 containing $\mathrm{H}_{2} \mathrm{O}$ were admitted into the $\mathrm{CIJ}$ mixer at a flow rate controlled through the syringe pump with $\sim 4 \mathrm{mg} \mathrm{s}^{-1}$ production ability for $\left(\mathrm{Ph}_{3} \mathrm{P}\right)_{2} \mathrm{Fe}(\mathrm{CO})_{3} @ \mathrm{PS}-\mathrm{c}-$ PAN NPs. The low energy and continuous process enables large scale production. For example, the reported production capability could reach $3.5 \mathrm{~kg}$ day $^{-1}$ using continuous-flow setup and commercial production of $\beta$ carotene nanoparticles were produced at $1,400 \mathrm{~kg}_{\text {day }}{ }^{-1}$ using CIJ technology [37].

\section{CONCLUSIONS}

In summary, we report a constrained-volume precipitation technique for the preparation of organometal-polymer assembly. Spherical nanocomposites composed of $\left(\mathrm{Ph}_{3} \mathrm{P}\right)_{2} \mathrm{Fe}(\mathrm{CO})_{3}$-confined PS-c-PAN NPs were converted into well-dispersed Fe-P-N-doped carbon with a high porosity. Controlling over distribution of dopants and nanostructure has been achieved by simply changing the processing parameters. The obtained multiple heteroatom-doped carbon catalysts provide a favorable structure for ORR and exhibit excellent electrocatalytic activity and stability. Tunable nanostructure and composition of Fe$\mathrm{P}-\mathrm{N}$-doped carbon lead to tailored catalytic ORR capability. Another significant advantage of our process is that the inherent continuous-flow feature makes particle production scalable. Therefore, the constrained-volume self-assembly is a promising approach in the rational design and preparation of a variety of nanocomposites for fuel cells, supercapacitors and metal-air batteries.

\section{Received 5 March 2018; accepted 31 March 2018;} published online 28 April 2018

1 Liu M, Zhang R, Chen W. Graphene-supported nanoelectrocatalysts for fuel cells: synthesis, properties, and applications.
Chem Rev, 2014, 114: 5117-5160

2 Jiang C, Ma J, Corre G, et al. Challenges in developing direct carbon fuel cells. Chem Soc Rev, 2017, 46: 2889-2912

3 Zeng X, Shui J, Liu X, et al. Single-atom to single-atom grafting of $\mathrm{Pt}_{1}$ onto $\mathrm{Fe}-\mathrm{N}_{4}$ center: $\mathrm{Pt}_{1} @ \mathrm{Fe}-\mathrm{N}-\mathrm{C}$ multifunctional electrocatalyst with significantly enhanced properties. Adv Energy Mater, 2018, 8: 1701345

4 Lu Y, Thia L, Fisher A, et al. Octahedral PtNi nanoparticles with controlled surface structure and composition for oxygen reduction reaction. Sci China Mater, 2017, 60: 1109-1120

5 Shang C, Yang M, Wang Z, et al. Encapsulated MnO in N-doping carbon nanofibers as efficient ORR electrocatalysts. Sci China Mater, 2017, 60: 937-946

$6 \mathrm{Wu} \mathrm{S}$, Zhu Y, Huo Y, et al. Bimetallic organic frameworks derived $\mathrm{CuNi} /$ carbon nanocomposites as efficient electrocatalysts for oxygen reduction reaction. Sci China Mater, 2017, 60: 654-663

7 Kuang $\mathrm{M}$, Wang $\mathrm{Q}$, Han $\mathrm{P}$, et al. Cu, Co-embedded $\mathrm{N}$-enriched mesoporous carbon for efficient oxygen reduction and hydrogen evolution reactions. Adv Energy Mater, 2017, 7: 1700193

8 Zhang G, Jin X, Li H, et al. N-doped crumpled graphene: bottomup synthesis and its superior oxygen reduction performance. Sci China Mater, 2016, 59: 337-347

9 Yan D, Guo L, Xie C, et al. N, P-dual doped carbon with trace Co and rich edge sites as highly efficient electrocatalyst for oxygen reduction reaction. Sci China Mater, 2018, 61: 679-685

10 Zhu L, Liu XQ, Jiang HL, et al. Metal-organic frameworks for heterogeneous basic catalysis. Chem Rev, 2017, 117: 8129-8176

$11 \mathrm{Lu} \mathrm{S}$, Zhuang Z. Electrocatalysts for hydrogen oxidation and evolution reactions. Sci China Mater, 2016, 59: 217-238

12 Ding W, Wei Z, Chen S, et al. Space-confinement-induced synthesis of pyridinic- and pyrrolic-nitrogen-doped graphene for the catalysis of oxygen reduction. Angew Chem, 2013, 125: 1197111975

13 Wang X, Lee JS, Zhu Q, et al. Ammonia-treated ordered mesoporous carbons as catalytic materials for oxygen reduction reaction. Chem Mater, 2010, 22: 2178-2180

14 Chen YZ, Wang C, Wu ZY, et al. From bimetallic metal-organic framework to porous carbon: high surface area and multicomponent active dopants for excellent electrocatalysis. Adv Mater, 2015, 27: 5010-5016

15 Sun $\mathrm{M}$, Zhang G, Liu $\mathrm{H}$, et al. $\alpha$ - and $\gamma-\mathrm{Fe}_{2} \mathrm{O}_{3}$ nanoparticle/nitrogen doped carbon nanotube catalysts for high-performance oxygen reduction reaction. Sci China Mater, 2015, 58: 683-692

16 Zhou R, Qiao SZ. An Fe/N co-doped graphitic carbon bulb for high-performance oxygen reduction reaction. Chem Commun, 2015, 51: 7516-7519

17 Fang X, Zang J, Wang X, et al. A multiple coating route to hollow carbon spheres with foam-like shells and their applications in supercapacitor and confined catalysis. J Mater Chem A, 2014, 2: 6191-6197

18 Wang Y, Kong B, Zhao D, et al. Strategies for developing transition metal phosphides as heterogeneous electrocatalysts for water splitting. Nano Today, 2017, 15: 26-55

19 Wangxi Z, Jie L, Gang W. Evolution of structure and properties of PAN precursors during their conversion to carbon fibers. Carbon, 2003, 41: 2805-2812

20 Nataraj SK, Yang KS, Aminabhavi TM. Polyacrylonitrile-based nanofibers-A state-of-the-art review. Prog Polymer Sci, 2012, 37: 487-513

21 Kowalewski T, Tsarevsky NV, Matyjaszewski K. Nanostructured 
carbon arrays from block copolymers of polyacrylonitrile. J Am Chem Soc, 2002, 124: 10632-10633

22 Zhong M, Kim EK, McGann JP, et al. Electrochemically active nitrogen-enriched nanocarbons with well-defined morphology synthesized by pyrolysis of self-assembled block copolymer. J Am Chem Soc, 2012, 134: 14846-14857

23 Leiston-Belanger JM, Penelle J, Russell TP. Synthesis and microphase separation of poly(styrene- $b$-acrylonitrile) prepared by sequential anionic and ATRP techniques. Macromolecules, 2006, 39: $1766-1770$

24 Lee K, Zhang J, Wang H, et al. Progress in the synthesis of carbon nanotube- and nanofiber-supported Pt electrocatalysts for PEM fuel cell catalysis. J Appl Electrochem, 2006, 36: 507-522

25 Huang J, Wang D, Hou H, et al. Electrospun palladium nanoparticle-loaded carbon nanofibers and their electrocatalytic activities towards hydrogen peroxide and NADH. Adv Funct Mater, 2008, 18: 441-448

26 Brunet JJ, Kindela FB, Neibecker D. Expedient synthesis of $\left(\mathrm{Ph}_{3}\right.$ $\mathrm{P})_{2} \mathrm{Fe}(\mathrm{CO})_{3}$. J Organomet Chem, 1989, 368: 209-212

27 Johnson BK, Prud'homme RK. Chemical processing and micromixing in confined impinging jets. AIChE J, 2003, 49: 2264-2282

28 Nikoubashman A, Lee VE, Sosa C, et al. Directed assembly of soft colloids through rapid solvent exchange. ACS Nano, 2016, 10: 1425-1433

29 He Y, Wang B, Hu X, et al. One-step constrained-volume synthesis of silver decorated polymer colloids with antimicrobial and sensing properties. Colloid Polym Sci, 2017, 295: 521-527

30 D'Addio SM, Prud'homme RK. Controlling drug nanoparticle formation by rapid precipitation. Adv Drug Deliver Rev, 2011, 63: 417-426

31 Saad WS, Prud'homme RK. Principles of nanoparticle formation by flash nanoprecipitation. Nano Today, 2016, 11: 212-227

32 Hayward RC, Pochan DJ. Tailored assemblies of block copolymers in solution: it is all about the process. Macromolecules, 2010, 43: 3577-3584

33 Kumar V, Adamson DH, Prud'homme RK. Fluorescent polymeric nanoparticles: aggregation and phase behavior of pyrene and amphotericin B molecules in nanoparticle cores. Small, 2010, 6: 29072914

34 Gindy ME, Panagiotopoulos AZ, Prud'homme RK. Composite block copolymer stabilized nanoparticles: simultaneous encapsulation of organic actives and inorganic nanostructures. Langmuir, 2008, 24: 83-90

35 Johnson BK, Prud'homme RK. Flash nanoprecipitation of organic actives and block copolymers using a confined impinging jets mixer. Aust J Chem, 2003, 56: 1021-1024

36 Akbulut M, Ginart P, Gindy ME, et al. Generic method of preparing multifunctional fluorescent nanoparticles using flash nanoprecipitation. Adv Funct Mater, 2009, 19: 718-725

37 Zhang C, Pansare VJ, Prud'Homme RK, et al. Flash nanoprecipitation of polystyrene nanoparticles. Soft Matter, 2012, 8: 86-93

38 Sosa C, Liu R, Tang C, et al. Soft multifaced and patchy colloids by constrained volume self-assembly. Macromolecules, 2016, 49: 3580-3585

39 Liu R, Sosa C, Yeh YW, et al. A one-step and scalable production route to metal nanocatalyst supported polymer nanospheres via flash nanoprecipitation. J Mater Chem A, 2014, 2: 17286-17290

40 Johnson BK, Prud'homme RK. Mechanism for rapid self-assembly of block copolymer nanoparticles. Phys Rev Lett, 2003, 91: 118302

41 Han J, Zhu Z, Qian H, et al. A simple confined impingement jets mixer for flash nanoprecipitation. J Pharmaceutical Sci, 2012, 101: 4018-4023

42 Wang $\mathrm{Y}$, Chen $\mathrm{X}$, Lin Q, et al. Nanoporous carbon derived from a functionalized metal-organic framework as a highly efficient oxygen reduction electrocatalyst. Nanoscale, 2017, 9: 862-868

43 Zhao L, Sui XL, Li JZ, et al. Supramolecular assembly promoted synthesis of three-dimensional nitrogen doped graphene frameworks as efficient electrocatalyst for oxygen reduction reaction and methanol electrooxidation. Appl Catal B-Environ, 2018, 231: 224233

44 Zhou X, Bai Z, Wu M, et al. 3-Dimensional porous N-doped graphene foam as a non-precious catalyst for the oxygen reduction reaction. J Mater Chem A, 2015, 3: 3343-3350

45 Zhao $\mathrm{P}$, Hua X, Xu W, et al. Metal-organic framework-derived hybrid of $\mathrm{Fe}_{3} \mathrm{C}$ nanorod-encapsulated, N-doped CNTs on porous carbon sheets for highly efficient oxygen reduction and water oxidation. Catal Sci Technol, 2016, 6: 6365-6371

46 Zhao X, Mao C, Luong KT, et al. Framework cationization by preemptive coordination of open metal sites for anion-exchange encapsulation of nucleotides and coenzymes. Angew Chem Int Ed, 2016, 55: 2768-2772

47 Jiang WJ, Gu L, Li L, et al. Understanding the high activity of Fe$\mathrm{N}-\mathrm{C}$ electrocatalysts in oxygen reduction: $\mathrm{Fe} / \mathrm{Fe}_{3} \mathrm{C}$ nanoparticles boost the activity of Fe- $\mathrm{N}_{x}$. J Am Chem Soc, 2016, 138: 3570-3578

48 Zhao L, Sui XL, Li JL, et al. 3D hierarchical Pt-nitrogen-dopedgraphene-carbonized commercially available sponge as a superior electrocatalyst for low-temperature fuel cells. ACS Appl Mater Interfaces, 2016, 8: 16026-16034

49 Chen YZ, Cai G, Wang Y, et al. Palladium nanoparticles stabilized with $\mathrm{N}$-doped porous carbons derived from metal-organic frameworks for selective catalysis in biofuel upgrade: the role of catalyst wettability. Green Chem, 2016, 18: 1212-1217

50 Li C, Chen Z, Ni Y, et al. Coordination compound-derived ordered mesoporous $\mathrm{N}$-free $\mathrm{Fe}-\mathrm{P}_{x}-\mathrm{C}$ material for efficient oxygen electroreduction. J Mater Chem A, 2016, 4: 14291-14297

51 Wang J, Li S, Zhu G, et al. Novel non-noble metal electrocatalysts synthesized by heat-treatment of iron terpyridine complexes for the oxygen reduction reaction. J Power Sources, 2013, 240: 381389

52 Deng C, Zhong H, Li X, et al. A highly efficient electrocatalyst for oxygen reduction reaction: phosphorus and nitrogen co-doped hierarchically ordered porous carbon derived from an iron-functionalized polymer. Nanoscale, 2016, 8: 1580-1587

53 Zhao L, Sui XL, Zhou QY, et al. 1D N-doped hierarchically porous hollow carbon tubes derived from supramolecular template as metal-free electrocatalysts for highly efficient oxygen reduction reaction. J Mater Chem A, 2018, 6: 6212-6219

54 Li C, Chen Z, Kong A, et al. High-rate oxygen electroreduction over metal-free graphene foams embedding $\mathrm{P}-\mathrm{N}$ coupled moieties in acidic media. J Mater Chem A, 2018, 6: 4145-4151

55 Kong A, Mao C, Wang Y, et al. Hierarchically porous few-layer porphyrinic carbon nanosheets formed by a $\mathrm{VO}_{x}$-templating method for high-efficiency oxygen electroreduction. J Mater Chem A, 2016, 4: 7305-7312

Acknowledgements This work was supported by the National Natural Science Foundation of China (21774095), Shanghai Municipal Natural Science Foundation (17ZR1432200), the Fundamental Research Funds for the Central Universities (0400219376), and the start-up funding from Tongji University and the Young Thousand Talented Program. 
Author contributions Liu R proposed the research and guided the whole project; $\mathrm{Li} \mathrm{C}$ performed the experiments and wrote the manuscript; Zhao J and Priestley RD helped analyze the data. All authors contributed to the general discussion and reviewed the manuscript.
Conflict of interest The authors declare no conflict of interest.

Supplementary information Experimental details are available in the online version of the paper.

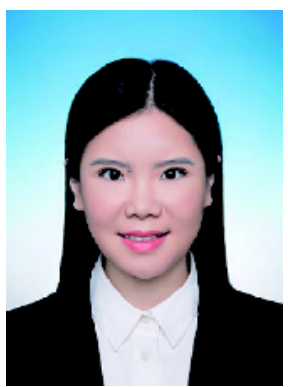

Congling Li received his $\mathrm{PhD}$ degree in chemistry from East China Normal University in 2017. In the same year, she carried out her postdoctoral research at Tongji University.

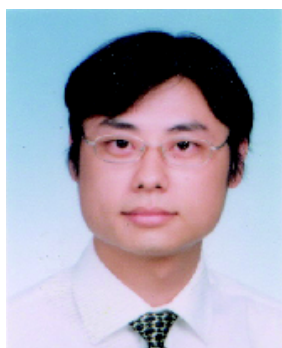

Rui Liu received his PhD degree in chemistry from the University of California, Riverside in 2010. He carried out his postdoctoral research at Oak Ridge National Laboratory from 2011 to 2012. In 2012-2015, he was a postdoctoral associate at Princeton University. In 2015, he was selected in Young Thousand Talented programe and joined Tongji University as a professor. His research interests include polymer self-assembly, carbon nanoparticles and energy applications.

\section{聚合物限域金属有机化合物自组装构筑高效多孔多元掺杂碳基氧还原催化剂}

李聪玲 ${ }^{1}$, 赵静 ${ }^{1}$, Rodney D. Priestley ${ }^{2}$, 刘 点 $^{1 *}$

摘要 非贵金属碳基纳米复合材料的设计和制备对于开发电解水及其燃料电池等技术的高效催化剂至关重要. 本文提出了一种连续沉淀 诱导形成胶体颗粒的限域自组装方法，其中疏水性金属有机化合物 $\left(\mathrm{Ph}_{3} \mathrm{P}\right)_{2} \mathrm{Fe}(\mathrm{CO})_{3}$ 被包裹在聚(苯乙烯-共聚-丙烯腈)纳米颗粒中. 具有限 域作用的聚合物能够确保 $\left(\mathrm{Ph}_{3} \mathrm{P}\right)_{2} \mathrm{Fe}(\mathrm{CO})_{3}$ 在高温热解过程中均匀碳化并分散在碳基质中, 成功制备出 $\mathrm{Fe}, \mathrm{P}$ 和 $\mathrm{N}$ 共掺杂的碳纳米颗粒, 其比 表面积高达 $380 \mathrm{~m}^{2} \mathrm{~g}^{-1}$. Fe-P-N掺杂的碳催化剂在酸性和碱性电解质中均表现出 4 电子的氧还原过程, 以及高的电催化活性和电化学稳定 性. 同时, 通过简单调节制备参数易于获得可调控催化活性的Fe-P-N掺杂碳基氧还原催化剂. 